OPEN ACCESS

Edited by:

Jack Wong,

Caritas Institute of Higher Education,

Hong Kong

Reviewed by:

Fuguo Xing,

Chinese Academy of Agricultural Sciences (CAAS), China

Lixin Xia,

Shenzhen University, China

*Correspondence: Sandra E. Vairo-Cavalli svairo@biol.unlp.edu.ar

Specialty section: This article was submitted to Antimicrobials, Resistance and

Chemotherapy,

a section of the journal

Frontiers in Microbiology

Received: 21 November 2020

Accepted: 19 January 2021

Published: 17 February 2021

Citation:

Fernández A, Colombo ML, Curto LM, Gómez GE, Delfino JM, Guzmán F, Bakás L, Malbrán I and

Vairo-Cavalli SE (2021) Peptides Derived From the $\alpha$-Core and $\gamma$-Core

Regions of a Putative Silybum marianum Flower Defensin Show Antifungal Activity Against Fusarium

graminearum

Front. Microbiol. 12:632008. doi: 10.3389/fmicb.2021.632008

\section{Peptides Derived From the $\alpha$-Core and $\gamma$-Core Regions of a Putative Silybum marianum Flower Defensin Show Antifungal Activity Against Fusarium graminearum}

\author{
Agustina Fernández ${ }^{1,2}$, Maria Laura Colombo', Lucrecia M. Curto ${ }^{2,3}$, Gabriela E. Gómez ${ }^{2,3}$, \\ José M. Delfino ${ }^{2,3}$, Fanny Guzmán ${ }^{4}$, Laura Bakás ${ }^{1,5}$, Ismael Malbrán ${ }^{2,6}$ and \\ Sandra E. Vairo-Cavalli ${ }^{1,2 *}$
}

${ }^{1}$ CIPROVE-Centro Asociado CIC, Departamento de Ciencias Biológicas, Facultad de Ciencias Exactas, Universidad Nacional de La Plata, La Plata, Argentina, ${ }^{2}$ Consejo Nacional de Investigaciones Cientificas y Técnicas (CONICET), Buenos Aires, Argentina, ${ }^{3}$ Instituto de Química y Fisicoquímica Biológicas (IQUIFIB), Universidad de Buenos Aires-CONICET, Buenos Aires, Argentina, ${ }^{4}$ Núcleo de Biotecnología Curauma (NBC), Pontificia Universidad Católica de Valparaíso, Valparaíso, Chile, ${ }^{5}$ Comisión de Investigaciones Científicas de la Provincia de Buenos Aires (CIC), Buenos Aires, Argentina, ${ }^{6}$ Centro de Investigaciones de Fitopatología (CIDEFI-UNLP-CIC), Facultad de Ciencias Agrarias y Forestales, Universidad Nacional de La Plata, La Plata, Argentina

Fusarium graminearum is the etiological agent of Fusarium head blight $(\mathrm{FHB})$, a disease that produces a significant decrease in wheat crop yield and it is further aggravated by the presence of mycotoxins in the affected grains that may cause health problems to humans and animals. Plant defensins and defensin-like proteins are antimicrobial peptides (AMPs); they are small basic, cysteine-rich peptides (CRPs) ubiquitously expressed in the plant kingdom and mostly involved in host defence. They present a highly variable sequence but a conserved structure. The $\gamma$-core located in the $\mathrm{C}$-terminal region of plant defensins has a conserved $\beta$-hairpin structure and is a well-known determinant of the antimicrobial activity among disulphide-containing AMPs. Another conserved motif of plant defensins is the $\alpha$-core located in the $\mathrm{N}$-terminal region, not conserved among the disulphide-containing AMPs, it has not been yet extensively studied. In this report, we have cloned the putative antimicrobial protein DefSm2, expressed in flowers of the wild plant Silybum marianum. The cDNA encodes a protein with two fused basic domains of an $\mathrm{N}$-terminal defensin domain (DefSm2-D) and a C-terminal Arg-rich and Lys-rich domain. To further characterize the DefSm2-D domain, we built a 3D template-based model that will serve to support the design of novel antifungal peptides. We have designed four potential antifungal peptides: two from the DefSm2-D $\alpha$-core region $\left(\mathrm{SmAP}_{\alpha 1-21}\right.$ and $\left.\mathrm{SmAP}_{\alpha 10-21}\right)$ and two from the $\gamma$-core region $\left(\mathrm{SmAP}_{\gamma 27-44}\right.$ and $\left.\mathrm{SmAP}_{\gamma 29-35}\right)$. We have chemically synthesized and purified the peptides and further characterized them by electrospray ionization mass spectrometry (ESI-MS) and Circular dichroism (CD) spectroscopy. $\mathrm{SmAP}_{\alpha 1-21}, \mathrm{SmAP}_{\alpha 10-21}$, and $\mathrm{SmAP}_{\gamma 27-44}$ inhibited the growth of the phytopathogen F. graminearum at low micromolar concentrations. Conidia exposure to the fungicidal 
concentration of the peptides caused membrane permeabilization to the fluorescent probe propidium iodide (PI), suggesting that this is one of the main contributing factors in fungal cell killing. Furthermore, conidia treated for $0.5 \mathrm{~h}$ showed cytoplasmic disorganization as observed by transmission electron microscopy (TEM). Remarkably, the peptides derived from the $\alpha$-core induced morphological changes on the conidia cell wall, which is a promising target since its distinctive biochemical and structural organization is absent in plant and mammalian cells.

Keywords: defensins, antimicrobial peptides, antifungal peptides, Fusarium graminearum, antifungal peptide design, fusarium head blight

\section{INTRODUCTION}

Wild plants and herbs provide a valuable source of antimicrobials because they exhibit a perfect adaptation to the environment, resulting in increased disease resistance relative to crop plants. Several highly active antimicrobial peptides (AMPs) have been isolated from different wild plant organs of the families Poaceae, Asteraceae, Ranunculaceae, and Caryophyllaceae (Astafieva et al., 2012). AMPs are important players in the immune response of plants against pathogens and pests; they comprise structurally diverse polypeptides that inhibit the growth of a wide range of microorganisms. Cysteine-rich peptides (CRPs) are AMPs particularly well represented in plants and they are divided into several families, including defensins. According to in silico studies from the analysis of complete plant genomes, most classes of cysteine-rich AMPs are much more abundant in the reproductive structures (Astafieva et al., 2012; Li et al., 2014). Although progress has recently been made recently in the identification of AMPs in seeds, those corresponding to flowers have been less studied (Astafieva et al., 2012). Concentrated in epidermal and stomatal cells, defensins are produced in areas that are likely to be the initial points of contact with pathogens (Parisi et al., 2018). Additionally, it was established that in the same species there are multiple defensin genes and this redundancy, necessary to protect the plant against selections of pathogens with higher tolerance to a particular type of defence molecule, is the result of the co-evolution of the immune systems of the plant and the pathogen (Vriens et al., 2014; Schmitt et al., 2016).

The main activity reported for plant defensins is antifungal, being active in micromolar concentrations (Hayes et al., 2013; Sagaram et al., 2013; Parisi et al., 2018). Besides antifungal activity, antibacterial, antiprotozoal and insecticidal action, inhibition of $\alpha$-amylase, trypsin and protein synthesis as well as blockage of ion channels have been established for these molecules (Spelbrink et al., 2004; Lin et al., 2007; Vijayan et al., 2013; Nascimento et al., 2015; Parisi et al., 2018). Plant defensins do not only act against plant pathogens, some of these molecules are effective against human pathogens and tumour cells as well (Vriens et al., 2015; Bleackley et al., 2016).

Regarding their structure, all defensins have in common the presence in their sequences of several cysteines that form multiple disulphide bridges and share a common cysteine-stabilized 3 -D fold $(C S \alpha / \beta)$ characterized by three antiparallel $\beta$-strands and one $\alpha$-helix. In view of the 3 -D conservation degree, any differences in defensin activity and specificity are likely to arise primarily from the considerable variation in the amino acid composition and the charge distribution of solvent-exposed loops. One of these loops is contained in the $\gamma$-core motif $\mathrm{GXC}\left(\mathrm{X}_{3-9}\right) \mathrm{C}$, a core pattern not limited to this defined AMP subclass but conserved across all classes of disulphide-stabilized AMPs. $\gamma$-core is a three-dimensional signature composed of two antiparallel $\beta$-sheets connected by a short turn region (Yount and Yeaman, 2004), which is considered the major determinant of antifungal activity of defensins (Sagaram et al., 2011; Muñoz et al., 2014). Defensins also contain a $\alpha$-core motif with a consensus sequence $\mathrm{GXC}\left(\mathrm{X}_{3-5}\right) \mathrm{C}$ not conserved in all disulphidecontaining AMPs. This motif resides in the $\beta 1$ strand- $\alpha$-helix loop and contains part of the $\alpha$-helix of each defensin; however, it lacks the hairpin structure of the $\gamma$-core motif (De Beer and Vivier, 2011; Sagaram et al., 2011).

More than $20 \%$ of global wheat (Triticum aestivum L.) production is lost annually due to the attack of pathogens and pests (Savary et al., 2019). Among the diseases affecting this crop in South America, Fusarium head blight (FHB), caused mainly by the fungal pathogen Fusarium graminearum Schwabe, is one of the most important (Savary et al., 2019). In Argentina, the frequency of occurrence of epidemics of FHB is currently increasing, with reported damages ranging from 20 to 70\% (De Galich, 1997; De Ackermann and Kohli, 2013). Beyond the yield and quality losses caused by this disease, the commercial value of affected grains is further diminished by their contamination with mycotoxins, mainly the trichothecenes deoxynivalenol (DON), nivalenol (NIV), and their acetylated forms (McCormick, 2003). Ingestion of these compounds by humans and cattle frequently results in anorexia, depression of immune responses, nausea, vomiting, and/or necrosis of the gastrointestinal tract, bone marrow, and lymphoid tissues (Malbrán et al., 2018).

The challenge of this work was to achieve the identification of a new defensin from a wild species of the Buenos Aires flora (Asteraceae family) and to perform its in silico structural and functional characterization to support the design and synthesis of new peptides that could be attractive molecules for their potential agricultural or medical application. The designed peptides include those regions corresponding to the $\alpha$-core or the $\gamma$-core motifs; their antifungal activity against 
the fungus F. graminearum was demonstrated and characterized. The use of the defensin sequence as a guide for peptide design could be a useful strategy for its potential application in the development of new antifungal compounds. It is well known that the $\gamma$-core motif contains major determinants of defensins antifungal activity and consequently it has already inspired the design of new antifungal compounds. The major contribution of this work was to demonstrate that the $\alpha$-core region could also serve as a promising avenue for that purpose.

\section{MATERIALS AND METHODS}

\section{Biological Material}

Flowers of Silybum marianum (L.) Gaertn. were collected during springtime from plants grown in La Plata, Buenos Aires (Argentina voucher specimen LPE 1162, Facultad de Ciencias Exactas, Universidad Nacional de La Plata, UNLP).

Fusarium graminearum SP1 was isolated from a grain sample obtained from San Pedro, Buenos Aires, Argentina. The strain was previously characterized as highly pathogenic and toxigenic both in vitro and in vivo (Malbrán et al., 2012, 2014).

\section{cDNA Cloning and Sequence Analysis}

Closed flower buds of $S$. marianum were ground using a mortar and pestle chilled with liquid nitrogen. Total RNA was isolated using a commercial plant-specific kit $\left(\right.$ RNeasy ${ }^{\circledR}$ Plant Mini Kit, QIAGEN, Hilden, Germany) according to the manufacturer's instructions. RNA was quantified by absorbance at $260 \mathrm{~nm}$, and its integrity was assessed in a $1 \%(w / v)$ agarose gel. Singlestranded cDNA was synthesized by retrotranscription of total RNA at $42^{\circ} \mathrm{C}$ for $60 \mathrm{~min}$ using the M-MuLV RT enzyme (Thermo Fisher Scientific, Waltham, MA) in a $50 \mu$ l reaction mixture containing reverse transcriptase buffer, dNTPs and the $\mathrm{R}_{0} \mathrm{R}_{1}$ Oligo(dT)18 primer: 5'-CCGGAATTCACTGCAGGGTAC CCAATACGACTCACTATAGGGCTTTTTTTTTTTTTTTT-3'. The cDNA synthesis control reaction consisted in amplifying the first strand with actin constitutive primers.

The resulting first strand of cDNA was subsequently used as a template for PCR amplification, using the degenerate forward primer 5'-AARAAYATHTGTGAAAAGCCAAGC-3' and the reverse primer $\left(\mathrm{R}_{0}\right): 5^{\prime}$-CCGGAATTCACTGCAG-3', designed from conserved $\mathrm{N}$-terminal ends of Asteraceae. The PCR procedure consisted in an initial denaturation step at $94^{\circ} \mathrm{C}$ for $5 \mathrm{~min}$, followed by 35 cycles of denaturation at $94^{\circ} \mathrm{C}$ for $45 \mathrm{~s}$, annealing at $56^{\circ} \mathrm{C}$ for $47 \mathrm{~s}$, and extension at $72^{\circ} \mathrm{C}$ for $4 \mathrm{~min}$, with a final $15 \mathrm{~min}$ extension at $72^{\circ} \mathrm{C}$. The amplified fragments were cloned into a pGEM-Teasy vector (Promega, Madison, WI, United States) and used to transform Escherichia coli XL1-Blue competent cells. Plasmids from positive colonies were purified using a commercial kit (Wizard ${ }^{\circledR}$ Plus SV Minipreps DNA Purification System, Promega), and both strands were sequenced by automated DNA sequencing. The resulting sequences were subjected to multiple sequence alignment (MSA) using the Basic Local Alignment Search Tool (BLAST) algorithm from the National Centre for Biotechnology Information (NCBI,
United States, https://blast.ncbi.nlm.nih.gov/Blast.cgi), and conserved domains were identified using NCBI's conserved domain-Search service (Marchler-Bauer et al., 2011).

\section{Bioinformatic Analyses}

Predicted defensin sequence (DefSm2-D) was used to perform a three-dimensional structural prediction by homology modelling. Fold assignment was performed using HHPred (Söding et al., 2005). Structural models were built with the program Modeller v 9.24 (Šali and Blundell, 1993) using ClustalW-derived alignments that were edited with GeneDoc software (version 2.7.000). NMR structure of Rs-AFP1 defensin from Raphanus sativus was used as template, Protein Data Bank ${ }^{1}$ code: 1AYJ. The quality of the model was assessed by using both energetic and structural criteria with PROSA II (Wiederstein and Sippl, 2007) and PROCHECK (Laskowski et al., 1993) software, respectively. Figures were drawn using PyMOL Molecular Graphics System (Version 1.2r3pre, Schrödinger, DeLano Scientific LLC, San Francisco, CA, United States). Functional prediction analysis was performed using the ProFunc server ${ }^{2}$ and the obtained structural model as input (Laskowski et al., 2005). The electrostatic Poisson-Boltzmann potential for the defensin structure was obtained through the APBS (Baker et al., 2001) molecular modelling software PyMOL with PARSE force field, optimized with the Python software package PDB2PQR (Dolinsky et al., 2004) and visualised in PyMOL.

\section{Peptide Design, Synthesis, and Purification}

Identification of putative antifungal motifs in the sequence of DefSm2-D laid the foundation for the rational design of potential antimicrobial peptides. To this aim, MSA of defensins that have been reported to have essential regions for antimicrobial activity as well as the location of these regions in the threedimensional model previously obtained from the cloned protein were considered. In turn, the peptides generated through the C-PAmP database (Niarchou et al., 2013) from sequences of available homologous defensins were also considered for the final design.

Peptides were synthesized using a Liberty Blue ${ }^{\mathrm{TM}}$ automated microwave peptide synthesizer (CEM Corp., Matthews, NC) following a standard 9-Fluorenyl methoxy carbonyl/tert-butyl (Fmoc/tBu) protocol. Fmoc-Rink Amide AM resin (Iris Biotech $\mathrm{GmbH}$, Marktredwitz, Germany) $0.74 \mathrm{mmol} / \mathrm{g}$ was used as solid support. Standard couplings of amino acids were carried out in $\mathrm{N}, \mathrm{N}$-dimethyl formamide (DMF) using $\mathrm{N}, \mathrm{N}$-diisopropylcarbodiimide (DIC)/OxymaPure ${ }^{\circledR}$ (Iris Biotech) activation and the corresponding amino acid. Fmoc removal was done with $20 \% \mathrm{v} / \mathrm{v}$ 4-methyl piperidine (4MP) in DMF. Peptides were cleaved with trifluoroacetic acid/ triisopropylsilane/2,2-(ethylenedioxy)diethanethiol/ultrapure water TFA/TIS/DOT/H20: 95/2.5/2,5/2.5 under gentle agitation over a period of $3 \mathrm{~h}$ at room temperature. After filtration, the

${ }^{1}$ www.rcsb.org

${ }^{2}$ http://www.ebi.ac.uk/thornton-srv/databases/profunc/ 
crude peptides were precipitated by the addition of cold diethyl ether, centrifuged, washed five times with cold diethyl ether, and dried. Ten milligrams of each crude peptide were dissolved in water and loaded onto a Clean-Up ${ }^{\circledR}$ CEC18153 column (UCT, Bristol, PA), previously washed twice with methanol and twice with water. Elution was performed with successive mixtures of $10,15,20,25,30$, and $60 \%(\mathrm{v} / \mathrm{v})$ acetonitrile in water. Fractions collected were evaporated using a Savant SPD1010 SpeedVac Concentrator (Thermo Fisher Scientific). To determine the main fractions containing the expected peptide, reversed-phase (RP)-high performance liquid chromatography (HPLC) analysis was performed on a XBridge ${ }^{\mathrm{TM}}$ BEH C18 column (Waters Corporation, Milford, MA, United States) using a 0-70\% acetonitrile gradient, with water containing $0.05 \%$ TFA as solvent A and acetonitrile containing $0.05 \%$ TFA as solvent $\mathrm{B}$, at a flow rate of $1 \mathrm{ml} / \mathrm{min}$ for $8 \mathrm{~min}$. The molecular mass of each peptide was determined by electrospray ionization mass spectrometry (ESI-MS) using a Shimadzu LCMS-2020 equipment (Shimadzu Corporation, Kyoto, Japan), in a $0-100 \%$ acetonitrile gradient for $20 \mathrm{~min}$. Peptides were stored as lyophilized dry powders at $-80^{\circ} \mathrm{C}$ and dissolved just before use.

\section{Circular Dichroism Spectroscopy}

Spectroscopic measurements were performed in the $180-250 \mathrm{~nm}$ wavelength range (far UV) to determine the secondary structure of the DefSm2-derived peptides. Peptide samples were dissolved in water, and in a 25:75 (v/v) trifluoroethanol (TFE): $\mathrm{H}_{2} \mathrm{O}$ mixture at approximately $0.25 \mathrm{mg} / \mathrm{ml}$ concentration, placed into a 1-mm path-length quartz cuvette at $25^{\circ} \mathrm{C}$, and measured in a Jasco J-810 spectropolarimeter (Jasco, Inc., Easton, MD, United States) at a scan speed of $20 \mathrm{~nm} / \mathrm{min}$ and $1 \mathrm{~s}$ time constant. Each spectrum in the plots results from the average of three successive scans, after applying a standard moving average window algorithm to smooth the trace. The solvent spectrum was measured similarly and subtracted from the corresponding spectra of peptides. Raw ellipticity data (mdeg) was converted to molar ellipticity, expressed in $\operatorname{deg} \mathrm{cm}^{2}$ $\mathrm{dmol}^{-1}$ units.

\section{Fungal Growth Inhibition Assay}

The peptides were tested for antifungal activity toward the filamentous fungi $F$. graminearum by performing hyphal growth inhibition assays according to the method of Bleackley et al. (2017) with slight modifications. Fungal isolates were grown under constant agitation on a carboxymethyl cellulose (CMC) sporulation medium (Cappellini and Peterson, 1965) at $170 \mathrm{rpm}$ and $25^{\circ} \mathrm{C}$ for 5-7 days until spores were abundantly produced. Macroconidia were collected after centrifugation at $5000 \mathrm{~min}^{-1}$ and $4^{\circ} \mathrm{C}$ for $15 \mathrm{~min}$, resuspended in half-strength potato dextrose broth (PD Broth) culture medium and adjusted to $\approx 5 \times 10^{4}$ spores $/ \mathrm{ml}$ using a hemocytometer. Aliquots $(90 \mu \mathrm{l})$ of the spore suspension were incubated for $48 \mathrm{~h}$ at $25^{\circ} \mathrm{C}$ in a 96 -well microplate with filter-sterilized peptide solutions $(10 \mu \mathrm{l})$ at different concentrations in water. Germination of spores was evaluated by measuring the optical density at $595 \mathrm{~nm}$ using a microplate reader Infinite M200 Pro (Tecan, Männedorf, Switzerland) after 0, 19, 24, 43, and $48 \mathrm{~h}$ of incubation. Each test was performed in triplicate. The minimum inhibitory concentration (MIC) was determined as the peptide concentration that completely inhibits fungal growth. Inhibition data were analysed by one-way ANOVA and the mean differences were evaluated at $p<0.05$ using the Tukey test. Statistical analyses were performed using the InfoStat software (Di Rienzo et al., 2018).

For the most active peptides, a time-to-kill experiment was performed amending half strength PD Broth media with the peptides at their MIC. Half strength PD Broth $(5 \mathrm{ml})$ was inoculated with macroconidia from $F$. graminearum SP1 to a final concentration of $1 \times 10^{4} \mathrm{conidia} / \mathrm{ml}$. Peptides were added at their MIC and the amended PD Broth was cultured for different periods: $0.5,1,3$, and $6 \mathrm{~h}$. A growth control was performed by incubating the conidia with water instead of peptide at $25^{\circ} \mathrm{C}$ in the dark for $48 \mathrm{~h}$. After each time period, $100 \mu \mathrm{l}$ of the $5 \mathrm{ml}$ culture were added to $900 \mu \mathrm{l}$ of sterilized water. This dilution was vortexed for $10 \mathrm{~s}$ and $100 \mu \mathrm{l}$ were plated onto three different half strength potato dextrose agar (PD Agar) plates and incubated for 3 days at $25^{\circ} \mathrm{C}$ in the dark before the colonies were counted. Each incubation time was replicated twice.

\section{Evaluation of Membrane Integrity}

The effect of peptides at their MIC values on conidia membrane permeability of F. graminearum was assessed using the membrane impermeant fluorescent red dye propidium iodide (PI; Thermo Fisher Scientific). Spore suspensions $\left(25 \mu \mathrm{l} ; \approx 10^{7}\right.$ spores $/ \mathrm{ml}$ in water) were amended with the peptide solutions prepared in water at their MIC and incubated for $30 \mathrm{~min}$ at $25^{\circ} \mathrm{C}$ before visualization by fluorescence microscopy. An aliquot $(5 \mu \mathrm{l})$ of PI $(0.1 \mathrm{mM})$ was added to each suspension. After $30 \mathrm{~min}$ of incubation at $25^{\circ} \mathrm{C}$, the uptake of the fluorescence probe was evaluated at $\lambda_{\mathrm{ex}} 545 \mathrm{~nm}$ and $\lambda_{\mathrm{em}} 580 \mathrm{~nm}$ using an Olympus ${ }^{\circledR}$ BX-51 (Olympus Optical, Tokyo, Japan) fluorescence microscope. Photographs were taken with an Olympus ${ }^{\circledR}$ A330 (Olympus Optical) adapted digital camera. Spores that fluoresced red after incubation with PI were classified as damaged, whereas those unstained were classified as intact cells. Water and the commercial cationic surfactant cetyl trimethyl ammonium bromide (CTAB, 0.8 mM; Cicarelli, Santa Fe, Argentina) were used as negative and positive controls, respectively. Each experiment, consisting of two replicates per treatment, was performed twice.

\section{TEM Imaging}

Transmission electron microscopy (TEM) was used to study the effects of the most active peptides on the ultrastructure of spores. F. graminearum conidia $\left(2 \times 10^{7} \mathrm{ml}^{-1}\right.$ in water $)$ were exposed to the most active peptides at their MIC for $1 \mathrm{~h}$ at $25^{\circ} \mathrm{C}$ and then prepared for electron microscopy imaging. The sample processing was carried out at room temperature and under gentle vacuum conditions ( $1 \mathrm{~atm}$ ). Conidia were fixed with $2.5 \%(\mathrm{v} / \mathrm{v})$ glutaraldehyde in $0.1 \mathrm{M}$ 
sodium cacodylate buffer $(\mathrm{pH} 7.2)$ for $3 \mathrm{~h}$ and postfixed for $2 \mathrm{~h}$ with $1 \%(\mathrm{w} / \mathrm{v})$ osmium tetroxide in $0.1 \mathrm{M}$ sodium cacodylate. Dehydration was carried out with aqueous ethanol solutions of increasing concentration (50 to $100 \%$ v/v). Finally, ethanol was replaced by acetone. The infiltration was performed with different proportions of acetone:spurr resin mixtures and the inclusion step was carried out in pure spurr resin. Ultrafine sections obtained by ultramicrotomy were contrasted with $1 \%(\mathrm{w} / \mathrm{v})$ uranyl acetate and lead citrate. A negative control was performed with water. Images were taken with a JEM 1200 EXII (Jeol Ltd., Akishima, Tokyo, Japan) microscope located at the TEM Service, Facultad de Ciencias Veterinarias, UNLP.

\section{RESULTS}

\section{cDNA Cloning and in silico Analysis}

To identify and further characterize S. marianum flower defensin, cDNA was synthesized using total RNA isolated from young flower buds by RT and the product of this reaction was used as template for PCR amplification. The $500 \mathrm{bp}$ amplified product was cloned, and several clones were sequenced. As a result, two different deduced amino acid sequences containing defensin domains were identified. These sequences exhibited high levels of similarity among themselves and with other plant defensins available in public databases. One of these cDNAs was selected for further characterization. Its nucleotide and deduced amino acid sequence are shown in Figure 1 (GenBank accession number: MK533801). This cDNA obtained encodes a protein of 95 amino acids containing an $\mathrm{N}$-terminal defensin domain (DefSm2-D) with a cysteine arrangement that clearly matches that present in C8 defensins: C-X10-C-X5-C-X3-C-X[9-10]-C$\mathrm{X}[6-8]-\mathrm{C}-\mathrm{X}-\mathrm{C}-\mathrm{X} 3-\mathrm{C}$ (Shafee et al., 2016) and a C-terminal Arg-rich and Lys-rich domain, of 54 and 41 amino acids, respectively. The deduced protein was designated as DefSm2. The BLAST Protein analysis of deduced amino acid sequence revealed that DefSm2-D showed 84\% identity with DmAMP1 from seeds of Dahlia merckii (Accession Number P0C8Y4),
64\% with AhAMP1 from seeds of Aesculus hippocastanum (Accession Number Q7M1F3) and 64\% with Art v 1 from pollen of Artemisia vulgaris (Accession Number CBK62707). The predicted molecular weights of the complete protein, defensin, and its C-terminal domain were 10.95, 6.10, and $4.87 \mathrm{kDa}$, respectively, and their corresponding isoelectric points were $9.01,8.50$, and 9.81 .

The amino acid sequence and the predicted 3D structure of DefSm2-D are shown in Figure 2A. As expected, deduced amino acid sequence analysis of DefSm2-D revealed the presence of the $\gamma$-core motif (GACHVRNGKHMC), presumably linked to antifungal activity, with four cationic residues. The analysis also revealed the presence of the $\alpha$-core motif (GNCGNPRHC) with two cationic residues.

An acceptable overall quality score (Z-score: -5.18 , according to PROSAII) was observed for the model, within the range characteristic for native proteins. The predicted 3D structure showed that most of the amino acid residues (98\%) were positioned in energetically favoured or allowed regions, revealing a good stereochemistry for the model, according to the Ramachandran plot (Supplementary Figure 1). A characteristic defensin structure was observed: the typical cysteine-stabilized alpha-beta $(\operatorname{CS} \alpha \beta)$ fold (Figure 2B). The structural model contains three antiparallel $\beta$-strands and one $\alpha$-helix connected by four disulphide bridges (Cys3-50, Cys14-35, Cys20-44, and Cys24-46). The $\gamma$-core motif resides in a hairpin loop between $\beta 2$ and $\beta 3$ strands, while the $\alpha$-core region comprises the Pro turn at the $\mathrm{N}$-terminus of the $\alpha$-helix and the proximal part of the loop connecting it to the $\beta 1$-strand (Figure 2B). Both regions show a predominantly positive electrostatic surface potential (Figure 2C).

Based on the analysis carried out with the ProFunc server, the most frequent Gene Ontology (GO) terms describing the putative function of the DefSm2D domain (cellular component, biological process, and molecular function) could be identified. Some of the most significant results for each GO term were extracellular component, defence, stress, and biotic stimulus response, the killing of cells from another organism and antifungal response.

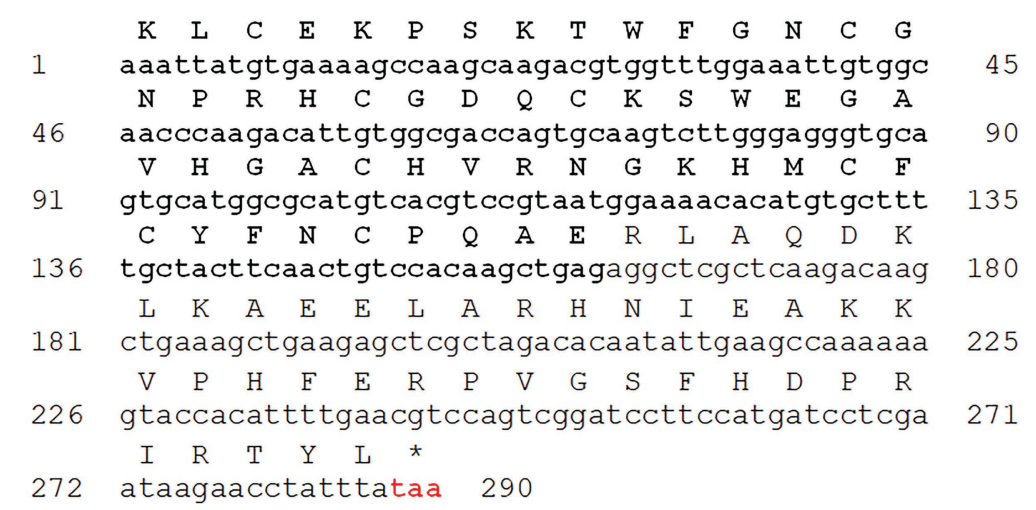

FIGURE 1 | cDNA sequence and deduced amino acid sequence of DefSm2 (GenBank accession number: MK533801). Defensin-like domain (DefSm2-D) is shown in bold. Stop codon (TAA) is red colored. 


\section{A}

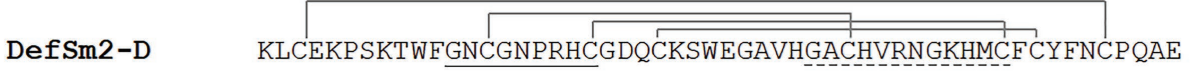

$\operatorname{SmAP}_{\alpha 1-21}$

$\operatorname{SmAP}_{\alpha 10-21}$

$\operatorname{SmAP}_{\gamma 27-44}$

$\operatorname{SmAP}_{\gamma 29-35}$

WEGAVHGACHVRNGKHMC

GAVHGAC

B

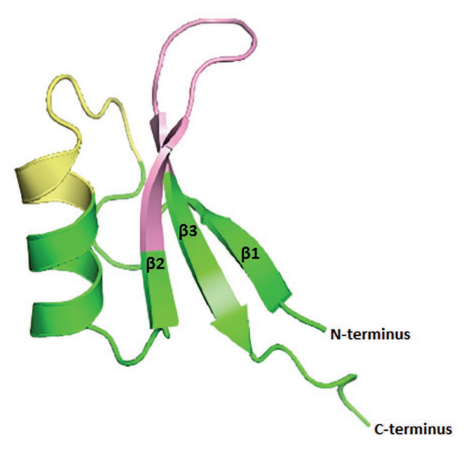

c
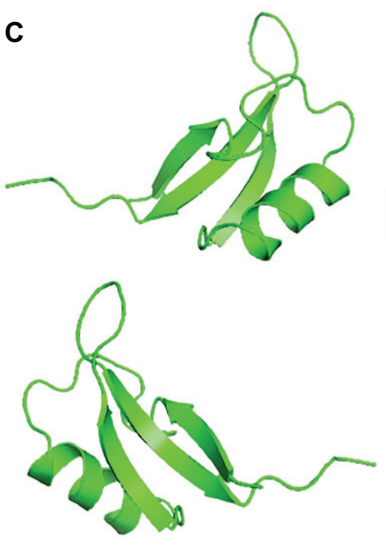
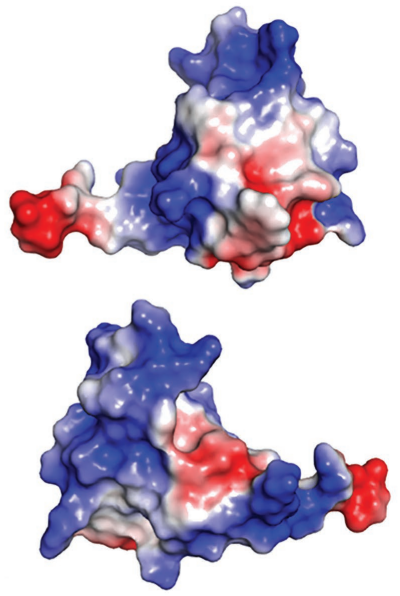

2.000

FIGURE 2 | (A) Amino acid sequence and secondary structure prediction of DefSm2-D. The $\beta$ strands are depicted with arrows and the $\alpha$-helix is represented with a cylinder. Disulphide bonds between Cys3-50, Cys14-35, Cys20-44, and Cys24-46 are shown above. The $\alpha$-core motif sequence is underlined with a continuous line, while the $\gamma$-core is underlined with a dashed line. The name and sequence of the synthesized peptides are shown below. (B) Homology-based model of DefSm2-D as a ribbon representation. The $\alpha$-core motif is indicated in yellow and the $\gamma$-core is indicated in pink. 3-D model was built using Modeller and visualised with PyMOL as described in Materials and Methods. (C) Electrostatic surface potential of DefSm2-D visualised with PyMOL. Negative charge is indicated in red, neutral charge in white and positive charge in blue as shown in the scale below (isocontour value of $\pm 2 \mathrm{kT} / \mathrm{e}$ ). The protein is represented by two plots corresponding to a rotation of $180^{\circ}$ around the vertical axis one from the other.

\section{Peptide Design, Synthesis, and Characterization}

The analysis of the potential antimicrobial peptide list generated with C-PAmP, using the sequences of the defensins with higher identity with DefSm2-D as input, showed that the predicted peptides were in the $\alpha$-core or $\gamma$-core regions of the protein. The score of the peptides located around both regions, as well as their position in the 3D structure of DefSm2-D, were considered for peptide design. Four peptides were synthesized through the F-moc strategy: two from DefSm2-D $\alpha$-core sequence (called $\mathrm{SmAP}_{\mathrm{al}-21}$ and $\mathrm{SmAP}_{\mathrm{a} 10-21}$ ), one from the $\gamma$-core (called $\left.\mathrm{SmAP}_{227-44}\right)$, and one smaller peptide contained in the latter (called $\mathrm{SmAP}_{\gamma 29-35}$ ). Table 1 summarizes the main characteristics of the designed peptides. The peptide $\mathrm{SmAP}_{\alpha 1-21}$ includes four additional charged amino acid residues: three cationic (Lys) and one anionic $(\mathrm{Glu})$ as compared to $\mathrm{SmAP}_{\text {a10-21 }}$.

Consistent with the lack of structure, the overall shape of CD spectra reveals that peptides adopt a predominant random coil conformation in water (Supplementary Figure 2). Trifluoroethanol is widely recognized as a useful co-solvent to assess the secondary structure propensity of peptides and proteins.
However, its general mode of action is to promote ( $\alpha$-helix and $\beta$-hairpin) secondary structure formation in polypeptides. After defying the molecules with this co-solvent, their far UV-CD spectra were measured to assess their structural behaviour. The $\mathrm{SmAP}_{\alpha 1-21}$ and $\mathrm{SmAP}_{\alpha 10-21}$ peptides, mapping to the $\alpha$-core sequence, show minimal enhancement of negative ellipticity bands located in the range of $215-230 \mathrm{~nm}$, pointing to a marginal gain of structure effect upon the TFE challenge. Nonetheless, for all four peptides the overall pattern of the far UV-CD bands, both in position and intensity, was maintained even at the high TFE concentration assayed $(25 \% \mathrm{v} / \mathrm{v})$. These results are consistent with intrinsic fluorescence emission spectra, which reveal that in all tryptophan-containing peptides this residue is mainly exposed to the aqueous solvent (results not shown).

\section{Antifungal Activity Assays}

The changes in the optical density over time in the presence of increasing concentrations of each peptide are shown in Figure 3A. Three peptides produced significant fungal inhibition when compared to the growth control (Figure 3B). 
TABLE 1 | Main properties of DefSm2-D derived peptides.

\begin{tabular}{|c|c|c|c|c|c|}
\hline Peptide name & Sequence & Molecular weight (Da) & $\mathrm{pl}^{1}$ & Net charge $^{2}$ & $\operatorname{MIC}(\mu \mathbf{M})^{3}$ \\
\hline $\mathrm{SmAP}_{\alpha 1-21}$ & KLCEKPSKTWFGNCGNPRHCG & 2361.7 & 9.0 & 4 & 32 \\
\hline $\mathrm{SmAP}_{\alpha 10-21}$ & WFGNCGNPRHCG & 1346.5 & 8.4 & 1.9 & 70 \\
\hline $\mathrm{SmAP}_{\gamma 29-35}$ & GAVHGAC & 613.9 & 6.7 & 0.9 & - \\
\hline $\mathrm{SmAP}_{\gamma 27-44}$ & WEGAVHGACHVRNGKHMC & 1991.3 & 8.1 & 3.8 & 20 \\
\hline
\end{tabular}

${ }^{1}$ Theoretical pl was calculated using the ExPASy tool Compute pl/Mw.

${ }^{2}$ Net charge was calculated at pH 5.5 ( $\mathrm{pH}$ of half strength PDB in which the antifungal test was performed).

${ }^{3}$ Minimum inhibitory concentration (MIC) is considered the minimal peptide concentration that completely inhibits F. graminearum growth.

Peptide $\mathrm{SmAP}_{\gamma 29-35}$ was tested at concentrations up to $100 \mu \mathrm{M}$ but did not show any antifungal activity (data not shown). For the remaining peptides, at concentrations under the MIC, exposure to increasing peptide concentrations does not affect the duration of the lag phase of the turbidimetric growth curves. As expected, comparison between both $\alpha$-core derived peptides revealed that the longer peptide is more effective than the shorter one.

In the time to kill experiment, $\operatorname{SmAP}_{\alpha 1-21}$ and $\operatorname{SmAP}_{\gamma 27-44}$ were lethal for conidia (Supplementary Figure 3). These peptides were able to exert their activity within $0.5 \mathrm{~h}$ of incubation at the assay conditions.

In addition, the uptake of PI was visible in fungal cells treated with $\mathrm{SmAP}_{\alpha 1-21}, \mathrm{SmAP}_{\alpha 10-21}$, and $\mathrm{SmAP}_{\gamma 27-44}$ (Figure 4). Interestingly, in the presence of the $\alpha$-core derived peptides macroconidia aggregate into network-like clusters (Figure 4, white arrows), which are more prominent for cells treated with $\mathrm{SmAP}_{\alpha 1-21}$ than for those treated with $\mathrm{SmAP}_{\alpha 10-21}$. Although $\mathrm{SmAP}_{\text {Y27-44 }}$ and the surfactant used as control also induce permeabilization of the F. graminearum spore membrane, clusters are not formed under any of these treatments.

Transmission electron microscopy images of conidia exposed to $\mathrm{SmAP}_{\alpha 1-21}$ reveal a scalloped appearance around the cells (Figure 5, black arrows). In addition, the cells present a granular and disorganized cytoplasm, suggesting that this peptide exerts a remarkable effect on the cell wall outermost layer. $\operatorname{SmAP}_{\gamma 27-44}$ does not produce the same effect, but some signs of cell deterioration could be seen, including segregation of the cytoplasm from the cell periphery (Figure 5, white arrow). In both cases, an increased electron density and the presence of a large number of electron-dense peroxisomes (Figure 5, white arrowheads) were observed with respect to the untreated cells.

\section{DISCUSSION}

The massive use of antifungal agents in the agriculture sector has led to the emergence of fungicide-resistant strains, restricting the number of commonly used compounds of this kind (Brauer et al., 2019) and probably contributing to developing resistance against antifungal medicines (Jampilek, 2016; Perfect, 2016). For FHB in particular, several factors further hinder the effectiveness of fungicide treatments, including lack of complete control by the available molecules, uneven flowering of wheat, and poor retention of fungicides on the spikes (Wegulo et al., 2015). In this context, there is an urgent need to search for new safe and effective antifungals. Wild plants and weeds naturally exhibit an enhanced pathogen resistance due to their perfect environment adaptation, constituting a valuable albeit unexplored source of natural AMPs (Slavokhotova et al., 2011) such as defensins. The wide range of pathogens that AMPs are active against and the varying levels of effectiveness that they exhibit could be attributed to the fact that these peptides have taken advantage of biochemical divergence and evolution of the cell wall and cell membrane composition, acting preferentially on pathogens whereas being harmless to the host (Teixeira et al., 2012). In view of its future applicability, a deep insight into the structure and function of natural AMPs is essential for future protein engineering and rational design of improved AMPs in view of its future applicability.

In this study, we report the identification of DefSm2, a putative antifungal protein with a defensin domain naturally expressed in flowers of the wild thistle S. marianum. Flowers are nutrient-rich structures that contain an abundance of protection molecules that serve as a front-line defence in peripheral cell layers (Silverstein et al., 2007). The in silico analysis of the cDNA derived-amino acid sequence of DefSm2 revealed the presence of two fused basic domains; the $\mathrm{N}$-terminal domain is a C8 defensin, while the C-terminal domain is rich in Arg and Lys. Of still unknown function, CRP fusions frequently occur in plant genomes and transcriptomes with other CRP, glycine-, or proline-rich protein domains. De Paula et al. (2011) described for Sd5, a defensin from Saccharum officinarum, the presence of an unstructured C-terminal region that has not been identified in any plant defensin structure reported in the Protein Data Bank with a predominance of hydrophobic amino acids as well as charged residues (Arg, Glu, and Lys) that participate in defensin-membrane interaction. A Lys-rich C-terminal domain was found in Ha-DEF1, a defensin from sunflower (Asteraceae) leaf and root (Letousey et al., 2007). By searching for homologous sequences, we have found predicted defensins in other species of the Asteraceae family fused to cationic C-terminal domains but just like for Ha-DEF1, those domains are shorter and have fewer cationic amino acids than DefSm2 C-terminal domain. Moreover, even though DefSm2-D shares high identity with predicted defensin domains from fused proteins of Cynara cardunculus var. scolymus (accession numbers XP_024967363 and XP_024968136), the DefSm2 C-terminal domain shares lower or no sequence identity with their predicted basic C-terminal domains. This intriguing and unique domain should have a precise function in $S$. marianum, a matter that still deserves proper consideration. 


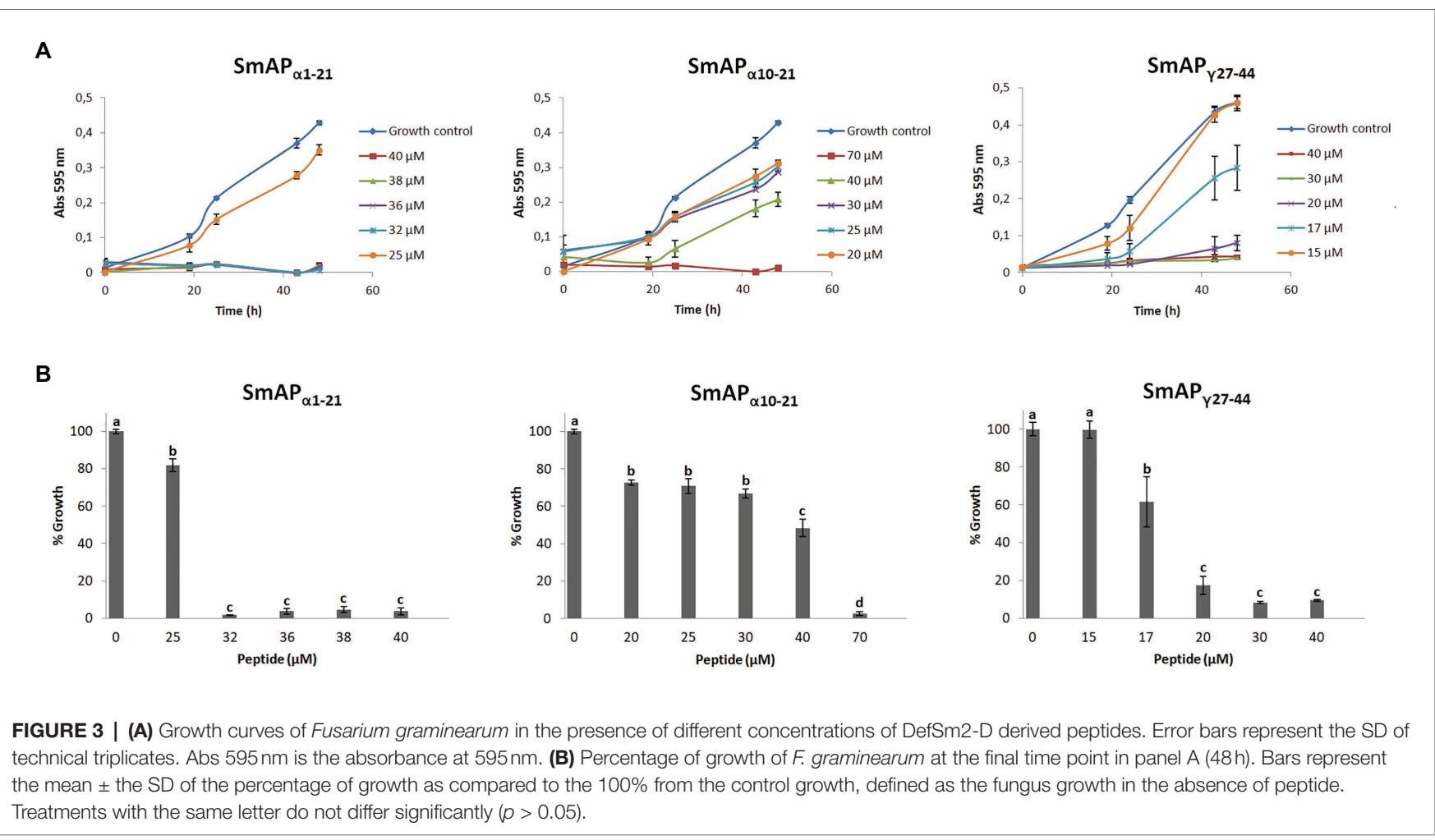

As CRP AMPs, plant defensins are held together by four disulphide bonds. The spacing and connectivity of the highly conserved cysteine residues define the plant defensin family (Shafee et al., 2016). According to our model, DefSm2-D disulphide connectivity is $1: 8,2: 5,3: 6$, and $4: 7$, which is common to C8 defensins. Disulphide bonds confer the molecule high resistance to proteases and to extreme values of $\mathrm{pH}$ and temperature, which is a valuable trait in the front line of the host-pathogen battle (De Coninck et al., 2013; Parisi et al., 2018). Furthermore, this disulphide-bonding network stabilizing the correct fold also seems to be central for many of defensin activities (Powers et al., 2005; Dhople et al., 2006). Most likely, this arrangement would facilitate the surface exposure of specific amino acid residues in the intervening loops, contributing to the establishment of interactions key for antimicrobial activity.

Notwithstanding their conserved tertiary structure, plant defensins share very low identity at the amino acid level. This sequence variability contributes to the different biological functions that have been attributed to these proteins, where a change of a single amino acid can alter the spectrum of activity exhibited by closely related defensins and can also account for their diverse antifungal modes of action (Thomma et al., 2003; Thevissen et al., 2007; Aerts et al., 2008). Amino acid residues at typically conserved positions are two glycine residues, an aromatic amino acid, and a glutamic acid (Ghag et al., 2016); the position numbers relative to DefSm2-D are Gly12 and Gly33, Trp10, and Glu28. It was proposed that these residues also contribute to the defensin structure stabilization and that the highly conserved Gly12 is present in all plant defensins, contributing to the plasticity of the loop, which is probably essential for the recognition process (De Medeiros et al., 2010). As expected, the deduced amino acid sequence analysis of DefSm2-D revealed the presence of the $\gamma$-core motif. Interestingly, we have found that this is identical to the DmAMP1 $\gamma$-core motif. DmAMP1 is active against Neurospora crassa, Fusarium solani, Fusarium culmorum (Osborn et al., 1995), and Saccharomyces cerevisiae among other fungi. On the other hand, the $\alpha$-core motif is also present in DefSm2-D, but it is not conserved in all disulphide-containing AMPs and differs from the $\beta$-hairpin structure of the $\gamma$-core motif. Although the overall similarity among defensin sequences is small, the loops where the $\alpha$ and $\gamma$-core are located constitute interacting regions with pathogen surface structures that can reach high identity scores when compared to defensins that share the same membrane target (De Medeiros et al., 2010). The Arg38 residue contained in the $\gamma$-core motif, although not conserved in all plant defensins, was reported to be crucial for the antifungal activity of MsDef1 against $F$. graminearum (Sagaram et al., 2011). Moreover, Arg38 is not only an important residue for antifungal activity in plant defensins but also for membrane interaction of human defensins with membranes of both Gram-positive and Gram-negative bacteria (Lee et al., 2016). Remarkably, this residue is present in DefSm2-D, and the derivative peptide $\mathrm{SmAP}_{\gamma 27-44}$ containing this Arg residue was the most active peptide against the aforementioned pathogen. Although positive charge prevalence is observed on the surface of DefSm2-D, according to our model, areas with a negative charge density are also observed, pointing to the small number of acidic residues also contributing to the polar face. 

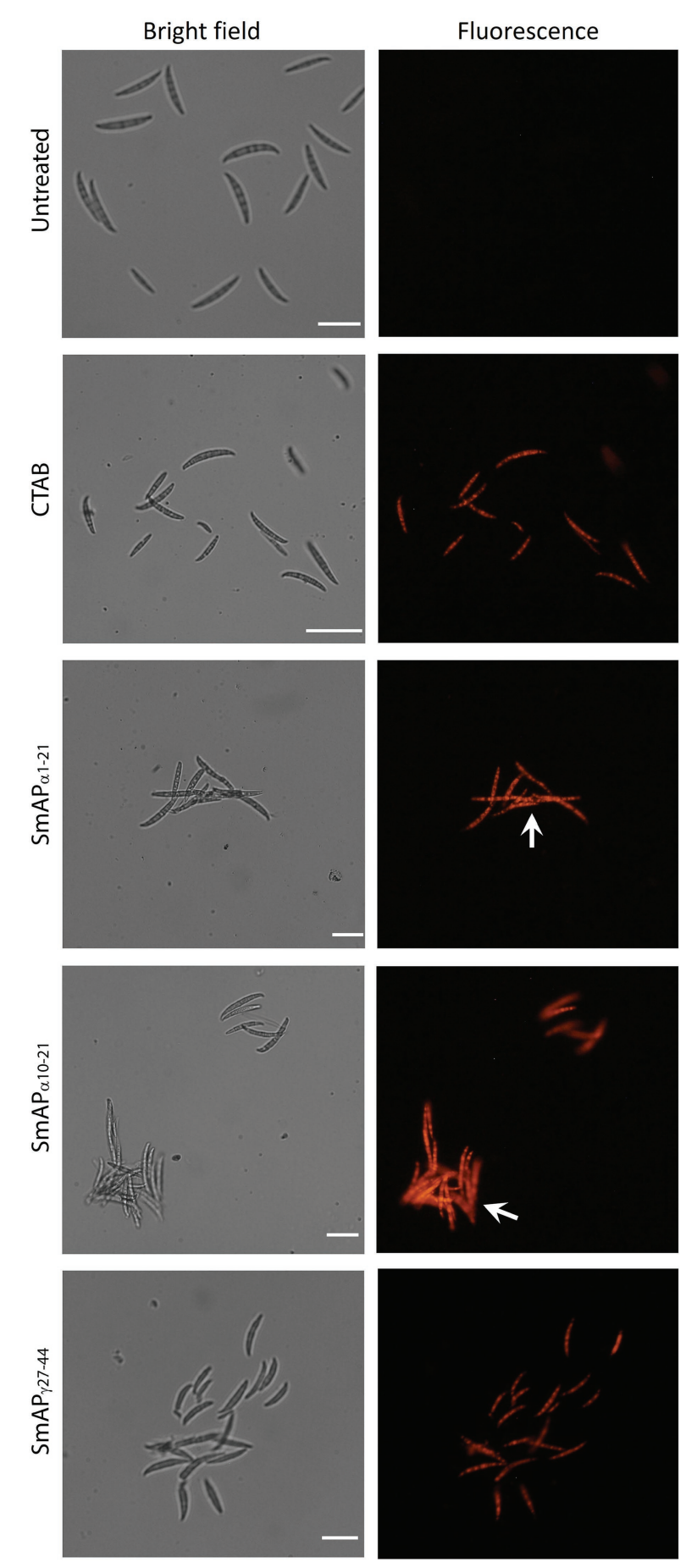

FIGURE 4 | Bright field (left) and fluorescence (right) images of

F. graminearum conidia incubated with peptides at their MIC for $1 \mathrm{~h}$. CTAB is the cationic surfactant cetyl trimethyl ammonium bromide, used as positive control. Peptides from the $\alpha$-core region, $\mathrm{SmAP}_{\alpha 1-21}$ and $\mathrm{SmAP}_{\alpha 10-21}$, produced the aggregation of conidia in clusters (white arrows). Scale Bar $=20 \mu \mathrm{M}$.

Many efforts have been made to identify minimal active motifs in defensins that would allow to creating new antimicrobial agents (De Medeiros et al., 2010). In fact, there are studies reporting a higher activity from peptides derived from a fulllength sequence than the source itself (Schaaper et al., 2001). Recently, Sathoff et al. (2019) showed that chemically synthesized peptides containing the $\gamma$-core motif of defensins may mimic the relative biological activity of the full-length defensin. On the contrary, Garrigues et al. (2017) found that PAF109, a peptide designed from the $\gamma$-core motif of the antifungal protein AfpB of fungal origin, does not show antifungal activity against several fungi evaluated. Muñoz et al. (2014) found that the synthetic peptides derived from the $\gamma$-core motif of MtDef4 and MsDef1 (from Medicago truncatula and Medicago sativa, respectively) possess specific antifungal properties that differ from those of the parental defensin. However, the fragmentation in many antimicrobial proteins and peptides can also generate activities that would not represent that of the parental molecule. In this work, we have designed four synthetic peptides from the $\alpha$ - and $\gamma$-core motifs of DefSm2-D, demonstrating the ability in three of them to inhibit the growth of the phytopathogen F. graminearum. Arg, Lys, as well as, His residues, are distributed along the regions selected for the design of $\mathrm{SmAP}_{\alpha 10-21}, \mathrm{SmAP}_{\alpha 1-}$ ${ }_{21}$, and $\mathrm{SmAP}_{\gamma 27-44}$. Compared to $\mathrm{SmAP}_{\alpha 10-21}$, the peptide $\operatorname{SmAP}_{\alpha 1-21}$ includes three extra cationic amino acids (Lys) and one anionic amino acid (Glu). A Trp residue is also present in the three active peptides synthesized, which is considered to play a pivotal function in the partition of AMPs in the membrane, anchoring the peptide at the membrane interface (Teixeira et al., 2012). In $\mathrm{SmAP}_{\alpha 1-21}$ and $\mathrm{SmAP}_{\alpha 10-21}$, Phe is adjacent to Gly, the first residues of the $\alpha$-core motif. In peptide $\mathrm{SmAP}_{\gamma 27-44}$, Phe is not present and the hydrophobicity, besides Trp, is ensured by the presence of Val and Met. The cationic amino acids would establish electrostatic interactions with negatively charged pathogen membranes or cell wall, while hydrophobic amino acids would contribute to the interactions at the lipid membrane interface in the target pathogen cell. Regardless of the specifics of the AMP mechanism of action, the first step appears to require site-specific binding targets on the pathogen cell wall and/or membrane (El-Mounadi et al., 2016; Cools et al., 2017). Circular dichroism evidence indicates that all peptides assayed remain unstructured in solution, with scant or no propensity to adopt a definite secondary structure (Supplementary Figure 2). Quite reasonably, the maintenance of plasticity along these stretches would enhance molecular recognition with target sites, in a picture fully consistent with the location of these dynamic and exposed motifs in the parent protein.

Much less studied is the role of the $\alpha$-core motif in antifungal activity and, to our knowledge, this is the first instance where peptides derived from this motif and its adjacent regions were shown to prevent fungal growth at micromolar concentrations. The $\alpha$-core motifs from MsDef1 and MtDef4 defensins were also chemically synthesized and tested for antifungal activity. Both GPCFSGC and GPCASDHNC peptides were totally inactive at all concentrations assayed, indicating that the $\alpha$-core motifs of MsDef1 and MtDef 4 per se do not exhibit antifungal activity. Peptides derived from the $\alpha$-core region from Brassica hybrid cv. Pule defensin exhibited activity against Colletotrichum gloeosporioides albeit at millimolar concentrations (Kaewklom et al., 2016). Probably, the $\alpha$ - and 

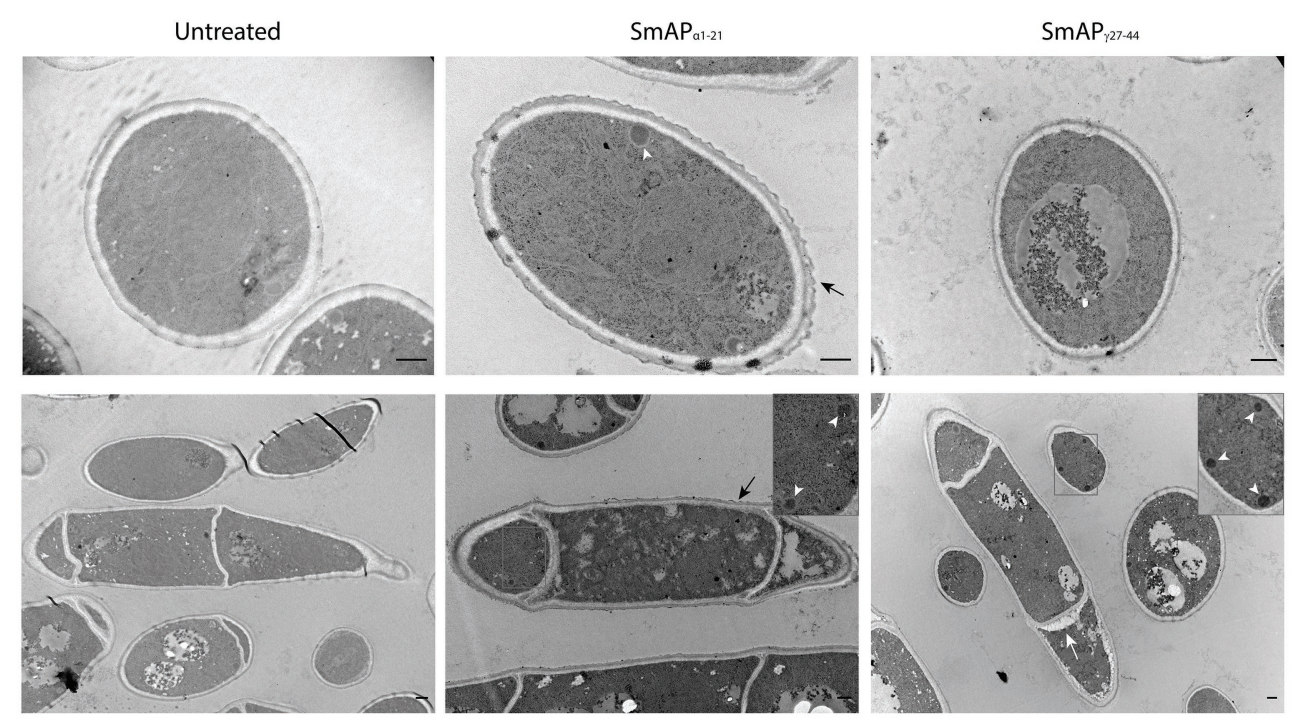

FIGURE 5 | Transmission electron microscopy (TEM) images of $F$. graminearum conidia incubated with peptides $\mathrm{SmAP}_{\alpha 1-21}$ and $\mathrm{SmAP}{ }_{\gamma 27-44}$ at their MIC for 30 min. A scalloped appearance was observed around the cells treated with $\mathrm{SmAP}_{\alpha 1-21}$ (black arrows). With $\mathrm{SmAP}_{\gamma 27-44}$, the cortical cytoplasm is separating from the cell wall (white arrow). In both cases, an increased electron density and the presence of electron-dense peroxisomes (zoom-in detail, white arrowheads) compared with the untreated cells were observed. Scale bar $=0.5 \mu \mathrm{m}$.

$\gamma$-core motifs require the presence of adjacent residues to display antifungal activity. Muñoz et al. (2014) found that the $\gamma$-core from MsDef1, a defensin active against $N$. crassa, does not show antifungal activity by itself, but a peptide spanning the $\gamma$-core six residues (including Trp, Arg, and Lys) of the defensin shows high inhibitory activity. In contrast, the $\gamma$-core from MtDef4, which presents three Arg residues, is almost as effective as the full defensin molecule against the above-mentioned fungus and the addition of extra amino acids towards the C-terminal end does not affect its biological activity. We decided to span the $\alpha$ - and $\gamma$-core from DefSm2-D towards the $\mathrm{N}$-terminal region in both cases, due to the presence of residues Lys and Trp that could potentially enhance antimicrobial activity. In fact, an increase in activity was verified for the peptide $\operatorname{SmAP}_{\alpha 1-21}$ compared to $\operatorname{SmAP}_{\alpha 10-21}$. $\mathrm{SmAP}_{\alpha 1-21}$ contains the $\mathrm{SmAP}_{\alpha 10-21}$ sequence but in addition it presents a higher net cationic charge given by the presence of three extra Lys residues. Similarly, two peptides of 10 amino acids from the $\mathrm{N}$-terminal region of a rice defensin (OsAFP1) were shown to be active against Candida albicans at micromolar concentrations. These peptides were designed among others as overlapping peptides from different regions that collectively covered the entire OsAFP1 sequence. Here again, the active $\mathrm{N}$-terminal peptides included both hydrophobic and cationic residues (Ochiai et al., 2018).

Using the PI uptake assay, we showed that peptides $\operatorname{SmAP}_{\alpha 1-}$ ${ }_{21}, \mathrm{SmAP}_{\alpha 10-21}$, and $\mathrm{SmAP}_{\gamma 27-44}$ permeabilized the plasma membrane of F. graminearum conidia. This dye penetrates into cells with damaged membranes and binds to nucleic acids, being therefore indicative of the loss of cell viability. All the conidia tested internalize the PI within $0.5 \mathrm{~h}$ of incubation when treated with peptides at their MICs, suggesting that membrane permeabilization is either a contributing factor for the antifungal activity of these peptides or a consequence of their action. Furthermore, short incubation periods in the presence of these peptides are enough to prevent conidia germination. In contrast with many reports of membrane permeabilization of fungi hyphae caused by defensin or derived peptides, our assays were performed on conidia that are resistant fungal structures endowed with thick cell walls, emphasizing the promising antimicrobial activity of the $S$. marianum DefSm2-D derived peptides. The presence of Phe and/or Trp as "hydrophobic anchors" and cationic residues could play a key role in membrane permeabilization. In this regard, Sagaram et al. (2011) clearly demonstrated the importance of the Phe residue in hexapeptide RGFRRR, which causes hypha permeabilization in F. graminearum, whereas the variant RGARRR is totally ineffective. Similarly, we propose that these aromatic hydrophobic residues bear an important role in the antifungal activity of $\mathrm{SmAP}_{\alpha 1-21}, \mathrm{SmAP}_{\alpha 10-21}$, and $\mathrm{SmAP}_{\gamma 27-44}$, as attested by the lack of activity shown for $\operatorname{SmAP}_{\gamma 29-35}$.

The effect of cell aggregation was recently observed by Velivelli et al. (2018) on the bacteria Xanthomonas campestris treated with MtDef5B, one of the two defensin domain from M. truncatula. These authors also found that the simultaneous replacement of His-Arg by Ala-Ala in the two $\gamma$-core motifs of MtDef5 (H36 and R37 in domain A and H93 and R94 in domain B) leads to a loss of bacterial cell killing effect, prevents the build-up of aggregates and induces the formation of bacteria chain-like structures. In $\mathrm{SmAP}_{\gamma 27-44}$, although an Arg residue is present equivalent to the Arg 37 position in MtDef5 there is no adjacent His and no visible aggregation is observed in the PI uptake assay. Conversely, the peptides derived from the DefSm2-D $\alpha$-core that present a His residue adjacent to Arg 
(R18 and H19 relative to DefSm2-D numbering) induce conidia aggregation.

The aggregation effect of the $\alpha$-core peptides on conidia could be further explained by the modifications on the conidia ultrastructure observed by TEM. Fungal cell walls are complex and dynamic structures, essential for cell viability, morphogenesis and pathogenesis, and are associated to many enzymes and metabolic pathways. They consist of an electron-lucent innermost layer, comprising a relatively conserved structural skeleton of chitin and $\beta$-glucan electron-dense and heterogeneous outer layers (Gow et al., 2003). TEM results indicate that this outermost protective layer would be the one most likely affected by the action of $\mathrm{SmAP}_{\alpha 1-21}$. The fungal cell wall constitutes a promising target for the development of antifungal compounds due to its unique biochemical and structural organization, which is absent in plant and mammalian cells. The effect of the peptides on several potential molecules including chemical components of the outermost layer, enzymes involved in the remodelling of the outer cell wall zone or messengers that trigger the observed fungal response could explain their antifungal effects.

The outer cell wall of $F$. graminearum conidia is formed by layers of $\alpha-(1,3)$ glucan with hydrophobic proteins called hydrophobins, which probably form a cover of rodlets that protect the spores (Quarantin et al., 2019). In Aspergillusfumigatus, a similar "rodlet layer" surface prevents immune recognition by both innate and adaptative immune defence systems in mammals (Aimanianda et al., 2009). In plant fungal infection, hydrophobins are required to penetrate the water-air interface and to attach to hydrophobic surfaces, such as the spike tissue. Furthermore, the simultaneous presence of different hydrophobins on the F. graminearum conidia surface could form a protecting shield against toxic compounds, turning this structure into a potential target for antifungal compounds. Regarding the enzymes responsible for remodelling and maintaining the cell wall, fungal cell death could be the result of the inhibition of the cell wall polysaccharide synthases (Latgé, 2007).

For $\mathrm{SmAP}_{\gamma 27-44}$, no apparent morphological changes were seen on the cell wall, but the observed shrunk cytoplasm detached from the cell wall might be indicative of early stage cell deterioration. A similar effect was observed by Sagaram et al. (2013) when treating F. graminearum hyphal cells with the defensin MtDef4. Moreover, for both $\mathrm{SmAP}_{\alpha 1-21}$ and $\mathrm{SmAP}_{\gamma 27-}$ ${ }_{44}$ peptides, a granulated electron-dense cytoplasm was observed, similarly to that observed with MtDef4 and Nad1 on F. graminearum and on F. oxysporum hyphal cells, respectively (van der Weerden et al., 2008; Sagaram et al., 2013).

Fungal pathogens present a remarkable genetic flexibility that contributes to the rapid evolution and adaptation to the host and the environment. To avoid the emergence of resistant strains, the development of new antifungal agents is needed. In this study, we report the antifungal activity of three synthetic peptides derived from the $\alpha$ - and $\gamma$-core region of DefSm2-D from the wild plant $S$. marianum against F. graminearum conidia. According to our results, for $\mathrm{SmAP}_{\alpha 1-21}$ derived from the $\alpha$-core, a fungal cell wall component could presumably act as the first peptide binding target site. Although this is not the most active peptide, we believe it is an interesting starting point for further development of new antifungal agents that might act on the fungal cell wall, a key structure in the pathogen resistance and in the evasion of host response. Furthermore, the differential cell wall composition of the pathogen with respect to the host would account for a selective action of the peptides on the fungus and not on the host cell. $\operatorname{SmAP}_{\gamma 27}$. ${ }_{44}$ instead, might induce fungal cell death through a different mechanism, probably independent of the cell wall target. Regardless of their precise mechanism of action, amino acid composition of the active peptides suggests that positively charged combined with aromatic amino acid residues are signature entities obligatory to attain antimicrobial activity. In this regard, our peptides would constitute promising antifungal agents since they are active in vitro against a resistant fungal structure such as the conidia. Further research is required in order to gain insight into the mechanism of action of these peptides.

\section{DATA AVAILABILITY STATEMENT}

The datasets presented in this study can be found in online repositories. The names of the repository and accession number can be found at: GenBank from the National Center for Biotechnology Information ${ }^{3}$ with the accession number MK533801 for DefSm2.

\section{AUTHOR CONTRIBUTIONS}

AF, MC, and SV-C: defensin cloning. AF, SV-C, and JD: bioinformatic analyses. AF, SV-C, and LB: peptide design and paper writing. FG: peptide synthesis and purification. LC, GG, and JD: circular dichroism spectroscopy. AF and IM: antifungal assays. AF and SV-C: TEM imaging. All authors contributed to the article and approved the submitted version.

\section{FUNDING}

This research work was financed by the National University of La Plata, Argentina (Project X-821), CONICET (PIP 0948), and FONDECYT 1170379. AF is CONICET fellow. LB is member of CICPBA Research Career Program. IM, LC, GG, JD, and SV-C are members of CONICET Research Career Program.

\section{SUPPLEMENTARY MATERIAL}

The Supplementary Material for this article can be found online at: https://www.frontiersin.org/articles/10.3389/fmicb.2021.632008/ full\#supplementary-material

${ }^{3}$ https://www.ncbi.nlm.nih.gov/genbank/ 


\section{REFERENCES}

Aerts, A. M., François, I. E. J. A., Cammue, B. P. A., and Thevissen, K. (2008). The mode of antifungal action of plant, insect and human defensins. Cell. Mol. Life Sci. 65, 2069-2079. doi: 10.1007/s00018-008-8035-0

Aimanianda, V., Bayry, J., Bozza, S., Kniemeyer, O., Perruccio, K., Elluru, S. R., et al. (2009). Surface hydrophobin prevents immune recognition of airborne fungal spores. Nature 460, 1117-1121. doi: 10.1038/nature08264

Astafieva, A. A., Rogozhin, E. A., Odintsova, T. I., Khadeeva, N. V., Grishin, E. V., and Egorov, T. A. (2012). Discovery of novel antimicrobial peptides with unusual cysteine motifs in dandelion Taraxacum officinale wigg. flowers. Peptides 36, 266-271. doi: 10.1016/j.peptides.2012.05.009

Baker, N. A., Sept, D., Simpson, J., Holst, M. J., and McCammon, J. A. (2001). Electrostatics of nanosystems: application to microtubules and the ribosome. Proc. Natl. Acad. Sci. U. S. A. 98, 10037-10041. doi: 10.1073/pnas. 181342398

De Beer, A., and Vivier, M. A. (2011). Four plant defensins from an indigenous south african brassicaceae species display divergent activities against two test pathogens despite high sequence similarity in the encoding genes. $B M C$ Res. Notes 4:459. doi: 10.1186/1756-0500-4-459

Bleackley, M., Dawson, C. S., McKenna, J. A., Quimbar, P., Hayes, B. M. E., van der Weerden, N. L., et al. (2017). Synergistic activity between two antifungal proteins, the plant defensin $\mathrm{NaD} 1$ and the bovine pancreatic trypsin inhibitor. $m$ Sphere 2, e00390-e00417. doi: 10.1128/mSphere.00390-17

Bleackley, M. R., Payne, J. A. E., Hayes, B. M. E., Durek, T., Craik, D. J., Shafee, T. M. A., et al. (2016). Nicotiana alata defensin chimeras reveal differences in the mechanism of fungal and tumor cell killing and an enhanced antifungal variant. Antimicrob. Agents Chemother. 60, 6302-6312. doi: 10.1128/AAC.01479-16

Brauer, V. S., Rezende, C. P., Pessoni, A. M., De Paula, R. G., Rangappa, K. S., Nayaka, S. C., et al. (2019). Antifungal agents in agriculture: friends and foes of public health. Biomolecules 9:521. doi: 10.3390/biom9100521

Cappellini, R. A., and Peterson, J. L. (1965). Macroconidium formation in submerged cultures by a non-sporulating strain of gibberella zeae. Mycologia 57, 962-966. doi: 10.2307/3756895

Cools, T. L., Struyfs, C., Cammue, B. P., and Thevissen, K. (2017). Antifungal plant defensins: increased insight in their mode of action as a basis for their use to combat fungal infections. Future Microbiol. 12, 441-454. doi: 10.2217/fmb-2016-0181

De Ackermann, M. D., and Kohli, M. M. (2013). "Chemical control of fusarium head blight of wheat" in Fusarium head blight in latin America. eds. A. M. Teresa M and C. S. Noemí (Dordrecht, Netherlands: Springer Netherlands), 175-189.

De Coninck, B., Cammue, B. P. A., and Thevissen, K. (2013). Modes of antifungal action and in planta functions of plant defensins and defensin-like peptides. Fungal Biol. Rev. 26, 109-120. doi: 10.1016/j.fbr.2012.10.002

De Galich, M. T. V. (1997). "Fusarium head blight in Argentina" in Fusarium head scab: Global status and future prospects. eds. H. J. Dubin, L. Gilchrist, J. Reeves and A. McNab (México: CIMMYT México D.F.), 19-28.

De Medeiros, L. N., Angeli, R., Sarzedas, C. G., Barreto-Bergter, E., Valente, A. P., Kurtenbach, E., et al. (2010). Backbone dynamics of the antifungal Psd1 pea defensin and its correlation with membrane interaction by NMR spectroscopy. Biochim. Biophys. Acta 1798, 105-113. doi: 10.1016/j. bbamem.2009.07.013

De Paula, V. S., Razzera, G., Barreto-Bergter, E., Almeida, F. C. L., and Valente, A. P. (2011). Portrayal of complex dynamic properties of sugarcane defensin 5 by NMR: multiple motions associated with membrane interaction. Structure 19, 26-36. doi: 10.1016/j.str.2010.11.011

Dhople, V., Krukemeyer, A., and Ramamoorthy, A. (2006). The human betadefensin-3, an antibacterial peptide with multiple biological functions. Biochim. Biophys. Acta 1758, 1499-1512. doi: 10.1016/j.bbamem.2006.07.007

Di Rienzo, J. A., Casanoves, F., Balzarini, M., Gonzalez, L. A., Tablada, M., and Robledo, C. W. (2018). "InfoStat." Córdoba, Argentina: Grupo InfoStat, FCA, Universidad Nacional de Córdoba. Available at: http://www.infostat.com.ar (Accessed May 15, 2020).

Dolinsky, T. J., Nielsen, J. E., McCammon, J. A., and Baker, N. A. (2004). PDB2PQR: an automated pipeline for the setup of poisson-boltzmann electrostatics calculations. Nucleic Acids Res. 32, W665-W667. doi: 10.1093/nar/gkh381

El-Mounadi, K., Islam, K. T., Hernández-Ortiz, P., Read, N. D., and Shah, D. M. (2016). Antifungal mechanisms of a plant defensin MtDef4 are not conserved between the ascomycete fungi Neurospora crassa and Fusarium graminearum. Mol. Microbiol. 100, 542-559. doi: 10.1111/mmi.13333

Garrigues, S., Gandía, M., Borics, A., Marx, F., Manzanares, P., and Marcos, J. F. (2017). Mapping and identification of antifungal peptides in the putative antifungal protein AfpB from the filamentous fungus Penicillium digitatum. Front. Microbiol. 8:592. doi: 10.3389/fmicb.2017.00592

Ghag, S. B., Shekhawat, U. K. S., and Ganapathi, T. R. (2016). "Plant defensins for the development of fungal pathogen resistance in transgenic crops: production, safety, regulation and public health" in Genetically modified organisms in food. eds. W. Ronald and P. Victor (Amsterdam, Netherlands: Elsevier Inc.), 381-396.

Gow, N. A. R., Latge, J. -P., Munro, C. A., De Groot, P. W. J., Hellingwerf, K. J., Klis, F. M., et al. (2003). Cell wall architecture in yeast: new structure and new challenges minireview cell wall architecture in yeast: new structure and new challenges ${ }^{\dagger}$. Yeast 9, 3341-3354. doi: 10.1128/microbiolspec.FUNK-0035-2016

Hayes, B. M. E., Bleackley, M. R., Wiltshire, J. L., Anderson, M. A., Traven, A., and van der Weerden, N. L. (2013). Identification and mechanism of action of the plant defensin nad 1 as a new member of the antifungal drug arsenal against Candida albicans. Antimicrob. Agents Chemother. 57, 3667-3675. doi: 10.1128/AAC.00365-13

Jampilek, J. (2016). Potential of agricultural fungicides for antifungal drug discovery. Expert Opin. Drug Discovery 11, 1-9. doi: 10.1517/17460441.2016.1110142

Kaewklom, S., Euanorasetr, J., Intra, B., Panbangred, W., and Aunpad, R. (2016). Antimicrobial activities of novel peptides derived from defensin genes of brassica hybrid Cv. pule. Int. J. Pept. Res. Ther. 22, 93-100. doi: 10.1007/ s10989-015-9488-2

Laskowski, R. A., MacArthur, M. W., Moss, D. S., and Thornton, J. M. (1993). PROCHECK: a program to check the stereochemical quality of protein structures. J. Appl. Crystallogr. 26, 283-291. doi: 10.1107/S0021889892009944

Laskowski, R. A., Watson, J. D., and Thornton, J. M. (2005). ProFunc: a server for predicting protein function from 3D structure. Nucleic Acids Res. 33, W89-W93. doi: 10.1093/nar/gki414

Latgé, J. -P. (2007). The cell wall: a carbohydrate armour for the fungal cell. Mol. Microbiol. 66, 279-290. doi: 10.1111/j.1365-2958.2007.05872.x

Lee, J., Jung, S. W., and Cho, A. E. (2016). Molecular insights into the adsorption mechanism of human $\beta$-defensin-3 on bacterial membranes. Langmuir 32, 1782-1790. doi: 10.1021/acs.langmuir.5b04113

Letousey, P., Marion, D., de Zélicourt, A., Thoiron, S., Simier, P., Elmorjani, K., et al. (2007). Ha-DEF1, a sunflower defensin, induces cell death in orobanche parasitic plants. Planta 226, 591-600. doi: 10.1007/s00425-007-0507-1

Li, Y. L., Dai, X. R., Yue, X., Gao, X. -Q., and Zhang, X. S. (2014). Identification of small secreted peptides (SSPs) in maize and expression analysis of partial SSP genes in reproductive tissues. Planta 240, 713-728. doi: 10.1007/ s00425-014-2123-1

Lin, K. -F., Lee, T. -R., Tsai, P. -H., Hsu, M. -P., Chen, C. -S., and Lyu, P. -C. (2007). Structure-based protein engineering for alpha-amylase inhibitory activity of plant defensin. Proteins 68, 530-540. doi: 10.1002/prot.21378

Malbrán, I., Mourelos, C. A., Girotti, J. R., Aulicino, M. B., Balatti, P. A., and Lori, G. A. (2012). Aggressiveness variation of Fusarium graminearum isolates from Argentina following point inoculation of field grown wheat spikes. Crop Prot. 42, 234-243. doi: 10.1016/j.cropro.2012.05.025

Malbrán, I., Mourelos, C. A., Girotti, J. R., Balatti, P. A., and Lori, G. A. (2014). Toxigenic capacity and trichothecene production by Fusarium graminearum isolates from Argentina and their relationship with aggressiveness and fungal expansion in the wheat spike. Phytopathology 104, 357-364. doi: 10.1094/PHYTO-06-13-0172-R

Malbrán, I., Mourelos, C. A., Girotti, J. R., and Lori, G. A. (2018). “Trichothecenes” in Handbook of foodborne diseases. ed. D. Liu (Boca Raton: CRC Press), 977-986.

Marchler-Bauer, A., Lu, S., Anderson, J. B., Chitsaz, F., Derbyshire, M. K., DeWeese-Scott, C., et al. (2011). CDD: a conserved domain database for the functional annotation of proteins. Nucleic Acids Res. 39, D225-D229. doi: $10.1093 /$ nar/gkq1189

McCormick, S. P. (2003). "The role of DON in pathogenicity" in Fusarium head blight of wheat and barley. eds. K. J. Leonard and W. R. Bushnell (St. Paul, Minnesota: The American Phytopathological Society), 165-183.

Muñoz, A., Chu, M., Marris, P. I., Sagaram, U. S., Kaur, J., Shah, D. M., et al. (2014). Specific domains of plant defensins differentially disrupt colony 
initiation, cell fusion and calcium homeostasis in neurospora crassa. Mol. Microbiol. 92, 1357-1374. doi: 10.1111/mmi.12634

Nascimento, V. V. D., Mello, E. D. O., Carvalho, L. P., De Melo, E. J. T., Carvlho, A. D. O., Fernandes, K. V. S., et al. (2015). PvD1 defensin, a plant antimicrobial peptide with inhibitory activity against leishmania amazonensis. Biosci. Rep. 35:e00248. doi: 10.1042/BSR20150060

Niarchou, A., Alexandridou, A., Athanasiadis, E., and Spyrou, G. (2013). C-PAmP: large scale analysis and database construction containing high scoring computationally predicted antimicrobial peptides for all the available plant species. PLoS One 8:e79728. doi: 10.1371/journal.pone.0079728

Ochiai, A., Ogawa, K., Fukuda, M., Ohori, M., Kanaoka, T., Tanaka, T., et al. (2018). Rice defensin OsAFP1 is a new drug candidate against human pathogenic fungi. Sci. Rep. 8:11434. doi: 10.1038/s41598-018-29715-w

Osborn, R. W., De Samblanx, G. W., Thevissen, K., Goderis, I., Torrekens, S., Van Leuven, F, et al. (1995). Isolation and characterisation of plant defensins from seeds of asteraceae, fabaceae, hippocastanaceae and saxifragaceae. FEBS Lett. 368, 257-262. doi: 10.1016/0014-5793(95)00666-w

Parisi, K., Shafee, T. M. A., Quimbar, P., van der Weerden, N. L., Bleackley, M. R., and Anderson, M. A. (2018). The evolution, function and mechanisms of action for plant defensins. Semin. Cell Dev. Biol. 88, 107-118. doi: 10.1016/j. semcdb.2018.02.004

Perfect, J. R. (2016). Is there an emerging need for new antifungals? Expert Opin. Emerg. Drugs 21, 129-131. doi: 10.1517/14728214.2016.1155554

Powers, J. -P. S., Tan, A., Ramamoorthy, A., and Hancock, R. E. W. (2005). Solution structure and interaction of the antimicrobial polyphemusins with lipid membranes. Biochemistry 44, 15504-15513. doi: 10.1021/bi051302m

Quarantin, A., Hadeler, B., Kröger, C., Schäfer, W., Favaron, F., Sella, L., et al. (2019). Different hydrophobins of Fusarium graminearum are involved in hyphal growth, attachment, water-air interface penetration and plant infection. Front. Microbiol. 10:751. doi: 10.3389/fmicb.2019.00751

Sagaram, U. S., El-Mounadi, K., Buchko, G. W., Berg, H. R., Kaur, J., Pandurangi, R. S., et al. (2013). Structural and functional studies of a phosphatidic acid-binding antifungal plant defensin MtDef4: identification of an RGFRRR motif governing fungal cell entry. PLoS One 8:e82485. doi: 10.1371/journal.pone.0082485

Sagaram, U. S., Pandurangi, R., Kaur, J., Smith, T. J., and Shah, D. M. (2011). Structure-activity determinants in antifungal plant defensins MsDef1 and MtDef4 with different modes of action against Fusarium graminearum. PLoS One 6:e18550. doi: 10.1371/journal.pone.0018550

Šali, A., and Blundell, T. L. (1993). Comparative protein modelling by satisfaction of spacial restraints. J. Mol. Biol. 34, 779-815. doi: 10.1006/jmbi.1993.1626

Sathoff, A. E., Velivelli, S., Shah, D. M., and Samac, D. A. (2019). Plant defensin peptides have antifungal and antibacterial activity against human and plant pathogens. Phytopathology 109, 402-408. doi: 10.1094/PHYTO-09-18-0331-R

Savary, S., Willocquet, L., Pethybridge, S. J., Esker, P., McRoberts, N., and Nelson, A. (2019). The global burden of pathogens and pests on major food crops. Nat. Ecol. Evol. 3, 430-439. doi: 10.1038/s41559-018-0793-y

Schaaper, W. M., Posthuma, G. A., Meloen, R. H., Plasman, H. H., Sijtsma, L., Van Amerongen, A., et al. (2001). Synthetic peptides derived from the B2-B3 loop of Raphanus sativus antifungal protein 2 that mimic the active site. J. Pept. Res. 57, 409-418. doi: 10.1034/j.1399-3011.2001.00842.x

Schmitt, P., Rosa, R. D., and Destoumieux-Garzón, D. (2016). An intimate link between antimicrobial peptide sequence diversity and binding to essential components of bacterial membranes. Biochim. Biophys. Acta 1858, 958-970. doi: 10.1016/j.bbamem.2015.10.011

Shafee, T. M. A., Lay, F. T., Hulett, M. D., and Anderson, M. A. (2016). The defensins consist of two independent, convergent protein superfamilies. Mol. Biol. Evol. 33, 2345-2356. doi: 10.1093/molbev/msw106

Silverstein, K. A. T., Moskal, W. A., Wu, H. C., Underwood, B. A., Graham, M. A., Town, C. D., et al. (2007). Small cysteine-rich peptides resembling antimicrobial peptides have been under-predicted in plants. Plant J. 51, 262-280. doi: 10.1111/j.1365-313X.2007.03136.x

Slavokhotova, A. A., Odintsova, T. I., Rogozhin, E. A., Musolyamov, A. K., Andreev, Y. A., Grishin, E. V., et al. (2011). Isolation, molecular cloning and antimicrobial activity of novel defensins from common chickweed (Stellaria media L.) seeds. Biochimie 93, 450-456. doi: 10.1016/j.biochi.2010.10.019

Söding, J., Biegert, A., and Lupas, A. N. (2005). The HHpred interactive server for protein homology detection and structure prediction. Nucleic Acids Res. 33, W244-W248. doi: 10.1093/nar/gki408

Spelbrink, R. G., Dilmac, N., Allen, A., Smith, T. J., Shah, D. M., and Hockerman, G. H. (2004). Differential antifungal and calcium channelblocking activity among structurally related plant defensins. Plant Physiol. 135, 2055-2067. doi: 10.1104/pp.104.040873

Teixeira, V., Feio, M. J., and Bastos, M. (2012). Role of lipids in the interaction of antimicrobial peptides with membranes. Prog. Lipid Res. 51, 149-177. doi: 10.1016/j.plipres.2011.12.005

Thevissen, K., Kristensen, H. -H., Thomma, B. P. H. J., Cammue, B. P. A., and François, I. E. J. A. (2007). Therapeutic potential of antifungal plant and insect defensins. Drug Discov. Today 12, 966-971. doi: 10.1016/j.drudis.2007.07.016

Thomma, B. P. H. J., Cammue, B. P. A., and Thevissen, K. (2003). Mode of action of plant defensins suggests therapeutic potential. Curr. Drug Targets Infect. Disord. 3, 1-8. doi: 10.2174/1568005033342000

van der Weerden, N. L., Lay, F. T., and Anderson, M. A. (2008). The plant defensin, NaD1, enters the cytoplasm of fusarium oxysporum hyphae. $J$. Biol. Chem. 283, 14445-14452. doi: 10.1074/jbc.M709867200

Velivelli, S. L. S., Islam, K. T., Hobson, E., and Shah, D. M. (2018). Modes of action of a bi-domain plant defensin MtDef5 against a bacterial pathogen xanthomonas campestris. Front. Microbiol. 9:934. doi: 10.3389/fmicb.2018.00934

Vijayan, S., Singh, N. K., Shukla, P., and Kirti, P. B. (2013). Defensin (TvD1) from Tephrosia villosa exhibited strong anti-insect and anti-fungal activities in transgenic tobacco plants. J. Pest Sci. 86, 337-344. doi: 10.1007/ s10340-012-0467-5

Vriens, K., Cammue, B. P. A., and Thevissen, K. (2014). Antifungal plant defensins: mechanisms of action and production. Molecules 19, 12280-12303. doi: 10.3390/molecules190812280

Vriens, K., Cools, T. L., Harvey, P. J., Craik, D. J., Spincemaille, P., Cassiman, D., et al. (2015). Synergistic activity of the plant defensin HsAFP1 and caspofungin against Candida albicans biofilms and planktonic cultures. PLoS One 10:e0132701. doi: 10.1371/journal.pone.0132701

Wegulo, S. N., Baenziger, P. S., Nopsa, J. F. H., Bockus, W. W., and Hallen-Adams, H. (2015). Management of fusarium head blight of wheat and barley. Crop Prot. 73, 100-107. doi: 10.1016/j.cropro.2015.02.025

Wiederstein, M., and Sippl, M. J. (2007). ProSA-web: interactive web service for the recognition of errors in three-dimensional structures of proteins. Nucleic Acids Res. 35, W407-W410. doi: 10.1093/nar/gkm290

Yount, N. Y., and Yeaman, M. R. (2004). Multidimensional signatures in antimicrobial peptides. Proc. Natl. Acad. Sci. U. S. A. 101, 7363-7368. doi: 10.1073/pnas.0401567101

Conflict of Interest: The authors declare that the research was conducted in the absence of any commercial or financial relationships that could be construed as a potential conflict of interest.

Copyright (๑ 2021 Fernández, Colombo, Curto, Gómez, Delfino, Guzmán, Bakás, Malbrán and Vairo-Cavalli. This is an open-access article distributed under the terms of the Creative Commons Attribution License (CC BY). The use, distribution or reproduction in other forums is permitted, provided the original author(s) and the copyright owner(s) are credited and that the original publication in this journal is cited, in accordance with accepted academic practice. No use, distribution or reproduction is permitted which does not comply with these terms. 